\title{
Study of Prevalence of Hypertension in School Going Children in Urban Delhi: A Cross Sectional Study
}

\author{
Hakim IS*, Vinod S, Ravi G, Lokesh CG, Virbhan B, Padmawati S, \\ Anwar S, Rajeev S, Sanjeev A \\ Department of cardiology, National Heart Institiute, New Delhi, India
}

Research Article

Volume 2 Issue 1

Received Date: May 08, 2018

Published Date: June 27, 2018

*Correspomding author: Hakim Irfan Showkat, MD, DNB Cardiology Scholar,

National Heart Institiute, East of Kailash, New Delhi, India 110065, India, Tel: 09990390305/9419028326; FAX:

01951255903; Email: docirfanshahi512@gmail.com

\section{Abstract}

1.1. Background: Early diagnosis of hypertension (HT) is an important strategy in its control. Previous studies have documented that hypertension may begin in adolescence, perhaps even in childhood. The purpose of this study was to determine the prevalence of hypertension and risk factors among school going children in Delhi, India.

Materials and Methods: School going children aged between 5 to 15 years of 10 different schools were selected and blood pressure measurements were taken. Prehypertension is considered when blood pressure is more than 90th percentile according to NIH 2005 guidelines.

Results: Total prevalence of prehypertension in the study was 3.1\%. The prevalence in boys was $3.2 \%$ and in girls was $2.9 \%$. Prevalence of obesity in prehypertension was $8.0 \%$ against normotensives $1.1 \%(P<0.05)$. Prevalence of hypertension in family members of prehypertensives was $18.6 \%$ and in normotensive $13.1 \%(P=0.1)$. Prevalence of diabetes mellitus in family members of prehypertensives was $23.4 \%$ and $13.7 \%$ in normotensives $(P<0.05)$.

Conclusion: Prevalence of pre hypertension was $3.1 \%$ in the study subjects. Obesity and family history of diabetes mellitus was found to be significantly associated with childhood hypertension.

Keywords: Hypertension; Prehypertensives; Normotensives; Parenchymal; Renovascular

\section{Introduction}

Systemic hypertension has been considered to be associated with adult population. But off late increased number of children are also being affected. Childhood hypertension is an established predictor of adult hypertension and organ damage and it is under estimated problem in developing countries [1]. Normal blood pressure values for children and adolescents are based on age, gender, height and are available in standardized tables. Primary HTN, once considered a rare occurrence in pediatric patients, is seen more often particularly in obese patients. Other factors responsible for increased prevalence of hypertension in children include life style changes such as decreased physical activity, increased intake of high calories, high sodium 
and low potassium foods, use of caffeinated and alcohol beverages, smoking, mental stress and sleep deprivation [2]. A secondary etiology of hypertension is much more likely in children than in adults with renal parenchymal disease and renovascular disease being the most common.

Children with hypertension should also be screened for other risk factors for cardiovascular disease, including diabetes mellitus and hyperlipidemia, and should be evaluated for target organ damage with a retinal examination, for renal damage and echocardiography. Hypertension in children is treated with lifestyle changes, including weight loss for those who are overweight or obese. A healthy, low-sodium diet; regular physical activity and avoidance of tobacco and alcohol. Children with symptomatic hypertension, target organ damage, diabetes, or persistent hypertension despite non pharmacologic measures should be treated with antihypertensive medications. Thiazide diuretics, angiotensin-converting enzyme inhibitors, angiotensin II receptor blockers, beta blockers, and calcium channel blockers are safe, effective and are well tolerated in children. Early detection of hypertension and its precipitating or aggravating factors is important if one is to evolve measures so that complications of hypertension can be prevented [3].

Obesity is one of the most important parameter consistently shown to be associated with hypertension. Early childhood obesity is associated with increased risk of subsequent morbidity whether or not obesity persists into adulthood [4].This study was an attempt to find out prevalence of HTN in children of 5- 15 years with respect to their age, sex, weight and height.

\section{Aims and Objectives}

To study the prevalence of hypertension in school going children and adolescents in Delhi with respect to age, sex, weight and height.

\section{Material and Methods}

This cross-sectional study was conducted at National Heart Institute and primary schools of Delhi. Ten Municipal Corporation schools of South Delhi were selected. The study was conducted from 01 July 2014 to 30 June 2015. Prior permission was obtained from all concerned. Ethical clearance was obtained. The age was determined from birth date of school registration record. Blood pressure and anthropometric data were collected. BP was measured using standardized sphygmomanometer with appropriate size cuff covering two third of the arm. The BP was measured with child in a sitting position, with arm at the level of heart and after a five minute rest.

Blood pressure percentiles were derived from the blood pressure tables as given in "The Fourth Report on the Diagnosis, Evaluation and Treatment of High Blood Pressure in Children and Adolescents" [5]. Height percentile was calculated from WHO height charts which is separate for boys and girls. In the present study to identify BP percentiles, first step was to refer to height percentile table and see what percentile of height the child was. Then, refer the values in BP percentile table corresponding to the child's sex, age and height percentile. Then according to value in the table and child's measurement, child was classified into specific category. Actual BP percentiles assume clinical significance in diagnosis, classification and treatment targets of HTN in children.

Systolic or diastolic BP equal to 95 percentile for gender, age and height for 3 or more occasions is defined as hypertension in children. Pre-HTN is defined as systolic BP or diastolic BP that are equal to 90 percentile but <95percentile. Stage 1 hypertension refers to BP from 95 percentile to the 99 percentile. Stage 2 HTN refers to values above stage 1 HTN. The 50 percentile of BP is the target attempted when hypertensive children are subjected to antihypertensive drug therapy [5].

Obesity was defined as BMI > 27 as per revised IAP Growth Charts for Height, Weight and Body Mass Index for 5- to 18-year-old Indian Children [6].

Statistical Analysis: Correlation regression analysis was done using Graphpad Instat 2 software.

\section{Results}

A total of 2010 students of 5 - 15 years of age were included, among which 1197 were boys and 813 were girls. As shown in table 1 there was increase in mean SBP and mean DBP with age up to $15+$ year of age. Linear regression model showed significant positive correlation between age and blood pressure both in boys and girls (Figures 1 and 2). Such increase in mean BP due to increase in age may be due to increase in body mass.

\begin{tabular}{|c|c|c|c|c|}
\hline & \multicolumn{2}{|c|}{ Systolic blood pressure (mm of Hg) } & \multicolumn{2}{c|}{ Diastolic blood pressure(mm of Hg) } \\
\hline Age (yrs) & Boys (Mean+ SD) & Girls (Mean + SD) & Boys (Mean + SD) & Girls (Mean + SD) \\
\hline $\mathbf{5 +}$ & $92.25+3.58$ & $91.15+5.12$ & $59.52+4.53$ & $57+3.40$ \\
\hline $\mathbf{6}+$ & $92.68+4.27$ & $92.65+4.15$ & $64.68+3.06$ & $64.43+3.03$ \\
\hline
\end{tabular}




\section{Epidemiology international journal}

\begin{tabular}{|c|c|c|c|c|}
\hline $\mathbf{7 +}$ & $92.38+2.55$ & $92.70+2.95$ & $64.90+3.25$ & $64.48+3.87$ \\
\hline $\mathbf{8}+$ & $95.20+5.26$ & $96.40+5.29$ & $64.40+5.20$ & $63.81+4.76$ \\
\hline $\mathbf{9 +}$ & $96.45+3.92$ & $98.13+3.74$ & $63.65+3.77$ & $63.61+4.07$ \\
\hline $\mathbf{1 0}+$ & $105.30+8.04$ & $98.21+3.94$ & $68.37+5.98$ & $66.22+3.34$ \\
\hline $\mathbf{1 1 +}$ & $108.59+6.69$ & $109.6+6.06$ & $64.57+6.73$ & $66.16+5.26$ \\
\hline $\mathbf{1 2}+$ & $109.09+8.01$ & $108.57+6.85$ & $64.65+8.74$ & $63.40+6.48$ \\
\hline $\mathbf{1 3 +}$ & $108.42+6.86$ & $108.62+7.03$ & $63.75+7.74$ & $64.26+7.66$ \\
\hline $\mathbf{1 4}+$ & $110.54+5.51$ & $103.95+5.80$ & $74.11+4.69$ & $71.73+4.70$ \\
\hline $\mathbf{1 5}+$ & $110.27+6.07$ & $109.73+5.98$ & $68+3.59$ & $65.23+6.24$ \\
\hline
\end{tabular}

Table 1: Mean SBP and DBP in boys and girls according to age.

Mean SBP and Age in Boys

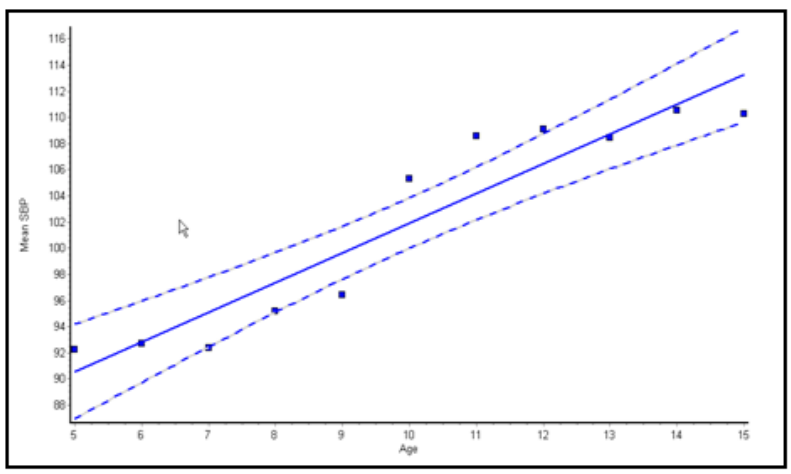

$\mathrm{r}^{2}=0.88, \mathrm{p}$ is $<0.0001$

\section{Mean DBP and Age in Boys}

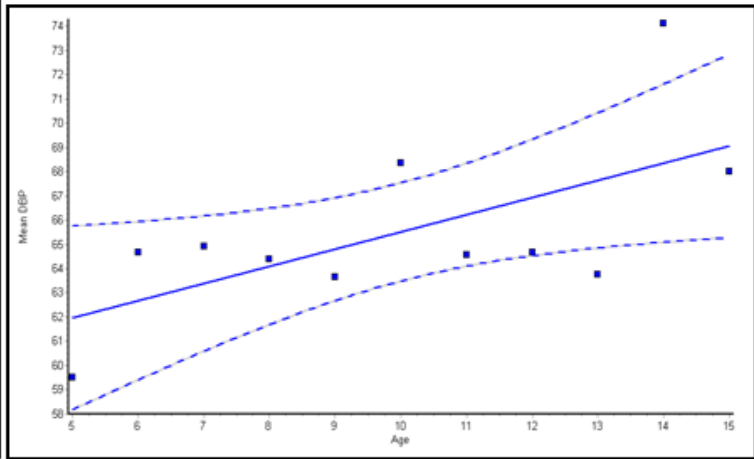

$\mathrm{r}^{2}=0.41, \mathrm{p}=0.03$

Figure 1: Correlation between age and blood pressure in boys.

Mean SBP and Age in Girls

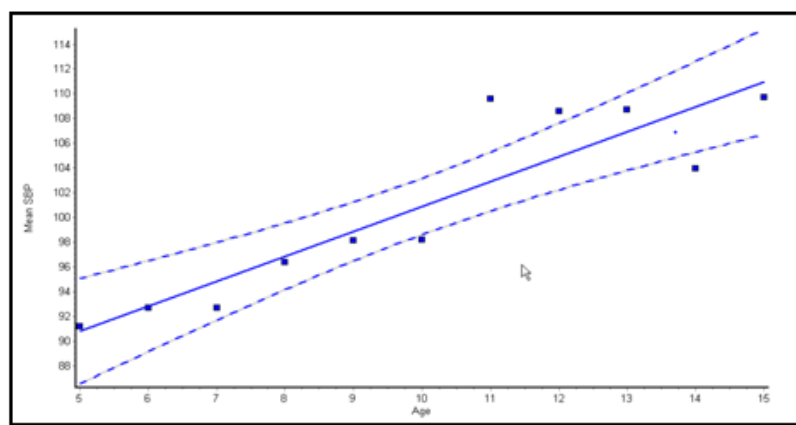

$\mathrm{r}^{2}=0.81, \mathrm{p}=0.0001$

\section{Mean DBP and Age in Girls}

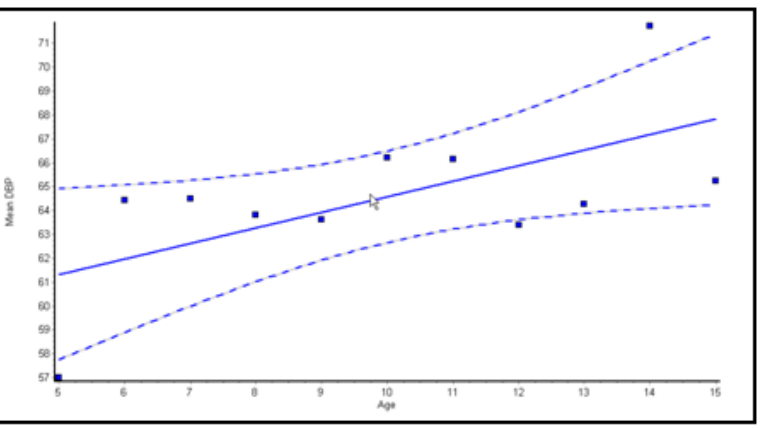

$\mathrm{r}^{2}=0.39, \mathrm{p}=0.0382$

Figure 2: Correlation between age and blood pressure in girls.

As shown in table 2, there were 63 students having pre-hypertension, high prevalence with $10.6 \%$ prevalence at the age of $12+$ in boys and in girls at 12 +year of age prevalence of pre-hypertension was
$5.1 \%$. Overall prevalence of pre-hypertension was 3.1\% in school going children between 5 - 15 years age. Slightly higher prevalence of pre-hypertension was seen in boys (3.2\%) compared to girls $(2.9 \%)$. 
Epidemiology international journal

\begin{tabular}{|c|c|c|c|c|c|c|}
\hline \multirow{2}{*}{$\begin{array}{c}\text { AGE } \\
\text { (yrs) }\end{array}$} & $\begin{array}{c}\text { No of } \\
\text { students }\end{array}$ & $\begin{array}{c}\text { Students having Pre- } \\
\text { hypertension }\end{array}$ & Percentage & $\begin{array}{c}\text { No of } \\
\text { students }\end{array}$ & $\begin{array}{c}\text { Students having Pre- } \\
\text { hypertension }\end{array}$ & Percentage \\
\hline $\mathbf{5 +}$ & 101 & 1 & 0.9 & 38 & 2 & 5.2 \\
\hline $\mathbf{6 +}$ & 67 & 2 & 2.9 & 45 & 2 & 4.4 \\
\hline $\mathbf{7 +}$ & 31 & 0 & 0 & 37 & 0 & 0 \\
\hline $\mathbf{8 +}$ & 83 & 4 & 4.8 & 44 & 2 & 0 \\
\hline $\mathbf{9 +}$ & 109 & 2 & 1.8 & 73 & 2 & 1.5 \\
\hline $\mathbf{1 0 +}$ & 179 & 4 & 2.2 & 132 & 2 & 2.6 \\
\hline $\mathbf{1 1 +}$ & 101 & 2 & 1.9 & 75 & 4 & 3.1 \\
\hline $\mathbf{1 2}+$ & 113 & 12 & 10.6 & 77 & 4 & 2.0 \\
\hline $\mathbf{1 3 +}$ & 107 & 4 & 3.7 & 106 & 2 & 4.4 \\
\hline $\mathbf{1 4}+$ & 197 & 6 & 3.0 & 97 & 4 & $\mathbf{2 . 9}$ \\
\hline $\mathbf{1 5 +}$ & 109 & 2 & 1.8 & 89 & $\mathbf{2 4}$ & \\
\hline All age & $\mathbf{1 1 9 7}$ & $\mathbf{3 9}$ & $\mathbf{3 . 2}$ & $\mathbf{8 1 3}$ & & 2 \\
\hline
\end{tabular}

Prevalence of hypertension in family members of pre hypertensives was $18.6 \%$ and in normotensive $13.1 \%(P=0.1)$. Prevalence of diabetes mellitus in family members of prehypertensives was $23.4 \%$ and $13.7 \%$ in normotensives $(P<0.05)$. Prevalence of obesity in prehypertensives was $8.0 \%$ against normotensives $1.1 \%(p<0.05)$.

Table 2: Prevalence of High BP in boys and girls in different age group.

\section{Discussion}

Hypertension is a major risk factor for cardiovascular and cerebro vascular diseases. Although the prevalence of hypertension is far less in children than in adult, there is enough evidence to suggest the root of essential hypertension extended into childhood [7]. A variety of studies conducted in different parts of the world revealed a vast range in the prevalence of hypertension in children showing as high as $22 \%$ to as low as $0.6 \%$ [8]. Chadha, et al. reported about $11.7 \%$ prevalence in school children of Delhi while Anand and Tandon, et al. reported $0.4 \%$ prevalence of hypertension in the age group of $5-17$ years $[3,9]$.

However, it has been observed that low hypertension in these populations may be mainly due to the use of an arbitrary criterion of hypertension assessment and not the recognized criterion of 95th percentile of blood pressure values. The prevalence of hypertension was found to be lower among girls than boys about 3.3\% in boys and $2.9 \%$ in girls. Prabhajot, et al. found the prevalence of hypertension in Amritsar, Punjab to be 8.3\% and $6.52 \%$ among boys and girls respectively [10]. The differences in patterns of blood pressure between males and females are probably related to certain biological and psychosocial factors.

In our study, both systolic and diastolic blood pressure of both genders showed positive correlation with height, which is in accordance to the finding of Gupta, et al. and Saha, et al. [11,12]. The mean SBP and DBP increased with increasing height. The prevalence of hypertension in students with height $<110 \mathrm{~cm}$ was $0.9 \%$, with height $111-120 \mathrm{~cm}$ was $4.7 \%$, with height $121-130$ $\mathrm{cm}$ was $2.3 \%$, with height $131-140 \mathrm{~cm}$ was $1.2 \%$, with height $141-150 \mathrm{~cm}$ was $4.1 \%$, with height $151-160 \mathrm{~cm}$ was $4.2 \%$ and with height $>160 \mathrm{~cm}$ was $2.6 \%$. The maximum numbers of students with hypertension were found in 151-160 cm height group.

The prevalence of hypertension increased with increasing age in females, i.e. $2.5 \%$ in $5-9$ years, $2.8 \%$ in $10-12$ years and $3.4 \%$ in $13-15$ years. The prevalence of hypertension increased with increasing age in males up to age 12 years, i.e. $2.3 \%$ in $5-9$ years, $4.6 \%$ in $10-12$ years and $2.9 \%$ in $13-15$ years. Also there was an increase in mean SBP and mean DBP with age up to 15 years of age. Such increase in mean BP and prevalence due to increase in age may be due to increase in body mass. Off the 63 hypertensive children, 15 belonged to $<10$ years age (i.e. 5-9 years) and 48 belonged to $>10$ years age (i.e. 10-12 \& 13-15). The reason why there was such high prevalence of hypertension in adolescent age group is not known but it could be due to some lifestyle modification.

All students with high blood pressure had prehypertension. Among 1197 boys, 39 had prehypertension and off 814 girls 24 had prehypertension. During study, 26 students had high blood pressure recorded on first visit but on 3 successive recordings they had normal blood pressure, so they were not included in prevalence rate. Studies indicate that blood pressure increases with age [13]. Population based epidemiological studies have shown that primary hypertension is far more common among apparently healthy children. Although the prevalence of hypertension is far less in children than in adults, there is enough evidence to suggest that the roots of essential hypertension extend into childhood [14]. 
The present study shows that SBP and DBP have a positive correlation with age, weight and BMI which is consistent with the previously reported studies on blood pressure in children [15]. In our study, a significant correlation of age was found with SBP as well as DBP, whereas Sarin et al reported a significant correlation between blood pressure and weight [15]. Voorset al reported that blood pressure correlates more closely to height and body mass than age [16]. An increase in SBP and DBP with age has also been reported in Indian children by other authors [17, 18]. Gupta et al observed a spurt in SBP between 13-15 years in both sexes [11]. The spurts in SBP between 1315 years are mainly related to certain biological and psychosocial factors and puberty timing. Children and adolescents with suspected white coat hypertension (WCH) should undergo ABPM. Diagnosis is based on the presence of mean systolic blood pressure (SBP) and diastolic blood pressure (DBP) [19].

The prevalence of hypertension, among school going children of Delhi, in our study was calculated to be $3.1 \%$ (63/2011 students). According to Chadha, et al. the prevalence of hypertension in school children, in Delhi is $11.7 \%$ [9]. He studied the urban school children where dietary habits, lack of physical activity and peer pressures could have contributed to such a high incidence. As our study was confined to municipal schools of Delhi, most of the students were from poor socio-economic background. One of the reasons for the low prevalence of hypertension in our study, in comparison to Chadha et al could be the lack of urban life style patterns. Previously, it was thought that the prevalence of hypertension in children in rural India would be less given their life style. However, Taksande, et al. showed a reasonably high prevalence of $5.75 \%$ $[17,18]$. This could probably be due to rapid urbanization of rural India which has altered the dietary habits, level of physical activity and social pressures of life. Routine performance of ABPM should be strongly considered in children and adolescents with high-risk conditions to assess HTN severity and determine if abnormal circadian BP patterns are present, which may indicate increased risk for target organ damage [19].

Evidence to support use of school measurements is limited. Though useful in research, because of insufficient evidence and lack of established protocols, the routine use of school based measurements to diagnose HTN cannot be recommended. School-based BP measurement, however, can be a useful tool to identify children who require formal evaluation as well as a helpful adjunct in monitoring diagnosed HTN [20].

Prevalence of obesity in prehypertensives was $8.0 \%$ against normotensives1.1\% ( $\mathrm{p}<0.05)$. Prevalence of hypertension in family members of prehypertensives was $18.6 \%$ and in normotensives $13.1 \% \quad(p=0.1)$. Prevalence of diabetes mellitus in family members of prehypertensives was $23.4 \%$ and $13.7 \%$ in normotensives $(\mathrm{p}<0.05)$.

\section{Limitations of study}

Some of the limitations of the study could be that private schools were not included in the study. This study may not reflect the true hypertension prevalence of society. Students above 15 years were excluded from the study. Inclusion of those students could have increased the prevalence of hypertension. Diagnosis of hypertension was based on three blood pressure recordings. Use of Ambulatory blood pressure monitoring on suspicious students could have given a more correct value. Due to low prevalence of childhood hypertension, a larger number of student populations could give a more true value.

\section{Conclusion}

The prevalence of pre-hypertension in school going children of 5-15 years of age was 3.1\%. Age and height positively correlated with both SBP and DBP. An increased prevalence of obesity was seen in pre hypertensives as against normotensive children. Children with a family history of diabetes were found to have more incidence of prehypertension than the rest with no family history.

\section{References}

1. Banker Chirag A, Jitesh Ca, Khyati Kakkad M, Panchsilla D (2013) A Study of Prevalence of Hypertension in School Children. Gujarat Medical Journal December 68 (2): 79-81.

2. Mitsnefes MM (2006) Hypertension in children and adolescent. Pediatr Clin North Am 53: 493-512.

3. Anand NK, Tandon L (1995) Prevalence of hypertension in school going children. Indian Pediatrics 33: 377-381.

4. Bagudai S, Nanda P, Satyanath RK (2014) Prevalence of obesity \& hypertension in adolescent school going children of Berhampur, Odisha, India. Int J Physiother Res 2(6): 777-780.

5. National High Blood Pressure Education Program Working Group on High Blood Pressure in Children and Adolescents (2004) The Fourth Report on the Diagnosis, Evaluation and Treatment of High Blood Pressure in Children and Adolescents. Pediatrics 114(2): 555-576. 


\section{Epidemiology international journal}

6. VV Khadilkar, AV Khadilkaretal (2015) Revised Indian Academy of Pediatrics 2015 growth charts for height, weight and body mass index for 5-18year-old Indian children. Indian J Endocrinol Metab 19(4): 470-476.

7. Sinaiko AR, Donahue RP, Jacobs Jr, Prineas RJ (1999) Relation of weight and rate of increase in weight during childhood and adolescence to body size, blood pressure, fasting insulin, and lipids in young adults. The Minneapolis Children's Blood Pressure Study. Circulation 99(11): 1471-1476.

8. Task Force on Blood Pressure Control in Children (1996) Report of the second Task Force on Blood Pressure Control in Children. Pediatrics 79: 1-25.

9. Chadha SL, Tandon R, Shekhawat S, Gopinath N (1999) An epidemiological study of blood pressure in school children (5-14 years) in Delhi. Indian Heart J 51(2): 178-182.

10. Prabhjot A, Kaur N, Kumari K, Sidhu S (2005) Variation in blood pressure among school children of Amritsar (Punjab). Anthropologist 7(3): 201-204.

11. Gupta AK, Ahmad AJ (1990) Normal blood pressure and evaluation of sustain blood pressure elevation in childhood. Indian Pediatr 27(1): 33-42.

12. Saha I, Raut BK, Paul B (2007) Anthropometric correlate of adolescent blood pressure. Indian J Public Health 51(3): 190-192.

13. Kaerney PM, Whelton M, Reynolds SK, Muntner P, Whelton PK, et al. (2005) Global burden of hypertension: Analysis of worldwide data. Lancet 365(9455): 217-223.

14. Kochanek KD, Smith BL (2004) Deaths: Preliminary data for 2002. Natl Vital Stat Rep 52(13): 1-47.

15. Sarin D, Chaturvedi P (1997) Normal blood pressure and prevalence of hypertension in school going children. JMGIMS 1: 32-35.

16. Voors AW, Webber LS, Frerichs RR, Berenson GS (1977) Body height and body mass as determinants of basal blood pressure in children-The Bogalusa Heart Study. Am J Epidemiol 106(2): 101-108.

17. Taksande A, Chaturvedi P, Vilhekar K, Jain M (2008) Distribution of blood pressure in school going children in rural area of Wardha district, Maharashatra, India. Ann Pediatr Card 1(2): 101106.

18. Aggarwal VK, Sharan R, Srivastava AK, Kumar P and Pandey CM (1983) Blood pressure profile in children of age 3-15 years. Indian Pediatr 20(12): 921-925.

19. Flynn JT, Kaelber DC, Baker Smith CM, Blowy D, Carroll AE, et al. (2017) AAP Subcommittee on Screening and Management of High Blood Pressure in Children. Clinical practice guideline for screening and management of high blood pressure in children and adolescents. Pediatrics. 140(3):e20171904

20. AAP Guidelines for Childhood Hypertension. American academy of pediatrics. 2017 